\title{
PENGARUH RAPAT ARUS PADA ANODIZE COLORING ALUMINIUM DENGAN PEWARNA TINTA PRINTER
}

\author{
Eko Yudiyanto, Muhammad Akhlis Rizza, Sarjiyana, Haris Puspito Buwono,* \\ Jurusan Teknik Mesin, Politeknik Negeri Malang \\ email: Koresponden penulis: haris.puspito@polinema.ac.id
}

(Artikel diterima: Februari 2020, direvisi: April 2020, diterima untuk terbit: Juli 2020)

\begin{abstract}
Abstrak - Proses anodize coloring untuk keperluan estetika yang baik menghasilkan warna aluminium sesuai dengan pewarna yang digunakan. Proses anodize coloring ini dilakukan dengan cara membersihkan aluminium, pembentukan aluminium oksida melalui proses anodizing dalam larutan asam sulfat dengan rapat arus dan durasi tertentu, pewarnaan, dan sealing. Pewarnaan dilakukan dengan memanfaatkan tinta printer yang tersedia secara komersial. Warna yang digunakan meliputi warna hitam, merah, kuning dan biru. Selanjutnya dilakukan analisis warna yang yang dihasilkan
\end{abstract}

Kata kunci: anodisasi, tinta printer, rapat arus

\section{Pendahuluan}

Proses pewarnaan secara anodisasi atau yang lebih populer dikenal dengan nama anodized coloring atau anodisasi warna merupakan proses yang mengontrol ketebalan, bentuk dan ukuran pori-pori lapisan aluminium oksida pada permukaannya. Proses ini telah digunakan secara komersial pada tahun 1923. Keberadaan lapisan oksida pada permukaan aluminium juga telah memberikan manfaat seperti ketahanan korosi, peningkatan kekerasan, dan keperluan estetika. ${ }^{1-4}$

Proses pewarnaan Aluminium melalui anodisasi dapat digambarkan seperti skema peralatan Gambar 1. Proses ini berupaya untuk mengontrol ketebalan dan besar kecilnya ukuran pori-pori aluminium oksida pada permukaan aluminium.

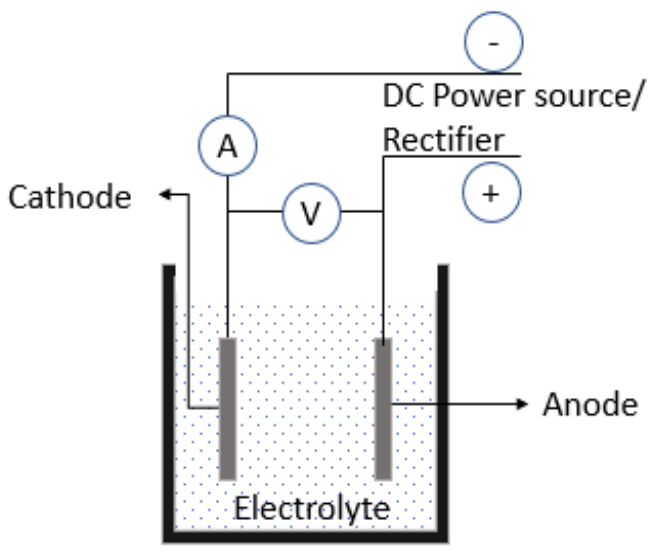

Gambar 1. Skema peralatan anodisasi

Aluminium sebagai benda kerja diberikan muatan positif pada catu daya searah (DC). Pemberian kutub positif ini menyebabkan aluminium berperan sebagai anoda, dan sebagai kutub negatif dapat digunakan elektroda lain seperti aluminium, baja, timbal, karbon atau jenis lainnya. Pada anoda terjadi reaksi oksidasi yang melepaskan ion aluminium ke dalam larutan yang mengakibatkan pembentukan ronggarongga atau pori-pori pada permukaan aluminium. Pori-pori yang terbentuk itu nantinya diisi dengan pewarna yang selanjutnya dijebak melalui proses sealing. Pada katoda atau elektroda tandem terjadi proses reduksi. Proses ini tidak menyebabkan pelarutan elektroda tandem ke dalam larutan. Proses ini juga tidak menyebabkan pembentukan prori-pori pada permukaan logam.

Proses ini dipengaruhi banyak faktor seperti jenis pembersihan, rapat arus, waktu, media elektrolit, pengadukan, temperatur, pengotor, jumlah langkah dan aerasi udara. ${ }^{5-12}$ Pembersihan secara kimiawi lebih disukai karena mampu menangani dimensi dan tingkat kekotoran aluminium yang bervariasi dengan hasil yang memuaskan.

Larutan yang berperan sebagai pewarna dapat berasal dari larutan garam logam tertentu, zat warna organik dan zat warna anorganik.

a. Zat Warna Organik.

Setelah aluminium diproses anodisasi dan dibilas dengan air bersih, lapisan oksida pada permukaan aluminium dapat diberi warna melalui pencelupan ke dalam larutan organik pada temperatur $65 \mathrm{C}$.

b. Zat Warna Anorganik.

Beberapa zat anorganik juga mampu diserap ke dalam lapisan aluminium. Proses penyerapan atau absorpsi ini terbagi menjadi dua tahap, yaitu meneruskan zat organik ke dalam pori-pori lapisan oksida, dan mengendapkan zat organik dalam pori-pori dengan larutan pengendapnya.

c. Pengendapan logam.

Seperti pada pewarnaan dengan zat organic, garam logam dapat diserapkan ke pori-pori lapisan oksida. Logam dari garam-garam tersebut diendapkan secara elektrolitik. Proses ini dilakukan melalui dua tahap, dimana tahap kedua adalah elektrolisa.

Contoh larutan pewarna anorganik untuk proses ini adalah warna kuning emas menggunakan ferric ammonium oxalate atau $\left(\mathrm{NH}_{4}\right)_{2} \mathrm{Fe}\left(\mathrm{C}_{2} \mathrm{O}_{4}\right)$, warna biru menggunakan senyawa, secara berurutan, $\mathrm{K} 4 \mathrm{Fe}(\mathrm{CN})_{6}$ dan $\mathrm{Fe}\left(\mathrm{NO}_{3}\right)_{3}{ }^{13}$

Proses pewarnaan melalui anodisasi menggunakan pewarna tinta printer warna biru terbukti mampu menghasilkan warna yang baik ${ }^{14}$. Hanya saja, tinta printer warna lainnya yaitu cyan, magenta, dan hitam belum dilaporkan sebagai alternatif pewarnaan pada anodized coloring yang handal. Untuk itu, perlu dilakukan penelitian kemungkinan penggunaan warna tinta selain warna biru. Untuk lebih memahami perilaku pewarnaan tersebut, penelitian juga dilakukan pada variasi rapat arus yang berbeda. Penelitian juga mempelajari sifat konduktifitas 
lapisan aluminium oksida yang diperoleh dari proses anodisasi.

\section{METODOLOGI}

Benda kerja proses anodisasi aluminium menggunakan aluminium tipe AA1100 yang berukuran $8.1 \mathrm{~mm}$ x $21.7 \mathrm{~mm}$ x $3 \mathrm{~mm}$. Proses penyiapan aluminium dimulai dari pemotongan, pemberian tanda atau kode dengan cara stamping untuk mempermudah identifikasi, pembuatan lubang pengait kawat konduktor dengan cara pengeboran menggunakan mesin bor tangan. Kemudian benda kerja dibersihkan melalui tujuh tahap pembersihan secara kimiawi. Zat-zat pembersih mempunyai grade teknis yang digunakan tanpa perlakuan pemurnian tambahan. Secara berurutan, tahap pembersihan adalah pembersihan menggunakan sabun, $10 \%$ larutan $\mathrm{NaOH}, 10 \% \mathrm{HCl}$, dan campuran $5 \%$ larutan $\mathrm{HNO}_{3}$ dan $80 \%$ larutan $\mathrm{H}_{3} \mathrm{PO}_{4}$. Durasi waktu setiap proses pembersihan adalah 3 menit, kecuali pada pembersihan terakhir dengan durasi 15 menit. Setiap selesai satu langkah pembersihan, benda kerja dibilas menggunakan air bersih (aquades).

Pada proses anodisasi hanya sebagian benda kerja yang dianodisasi atau yang dicelupkan ke dalam larutan asam sulfat. Ukuran aluminium yang tercelup adalah $6.1 \mathrm{~mm}$ x 21.7 $\mathrm{mm}$ x $3 \mathrm{~mm}$. Setelah proses pembersihan, selanjutnya dilakukan proses pembentukan pori-pori permukaan dimasukan ke dalam 15\% larutan $\mathrm{H}_{2} \mathrm{SO}_{4}$ dengan arus dan waktu sesuai dengan variabel yang telah ditentukan. Perbandingan katoda terhadap anoda adalah 1:1 dan jarak antar keduanya adalah $8 \mathrm{~cm}$. Proses anodisasi dilangsungkan pada temperatur kamar $\left(27^{\circ} \mathrm{C}\right)$ tanpa pengadukan dan aerasi..

Setelah proses anodisasi, benda kerja dibersihkan menggunakan air bersih kemudian dilakukan tahap pewarnaan aluminium dengan menggunakan larutan pewarna yaitu tinta Exxxx pada temperatur $50^{\circ} \mathrm{C}$ dengan durasi 5 menit. Selanjutnya benda kerja dibilas menggunakan air bersih (aquades) dan dilanjutkan sealing atau dimasukkan ke dalam air panas untuk penutupan pori-pori.

Identifikasi warna standar RGB dan HEX dilakukan menggunakan software color identifier yaitu colorcodepicker.com dengan menggunakan jenis warna yang paling dominan. Pengujian konduktivitas konduktor baik alumium maupun tembaga menggunakan ohm-meter.

Tabel 1. Identitas benda kerja dan parameter.

\begin{tabular}{|c|c|c|}
\hline Kode Benda* & $\begin{array}{c}\text { Rapat Arus } \\
\left(\mathbf{A} / \mathbf{c m}^{\mathbf{2}}\right)\end{array}$ & $\begin{array}{c}\text { Waktu } \\
\text { (menit) }\end{array}$ \\
\hline $1 \mathrm{~T} 1001$ & 0.01 & 90 \\
\hline $2 \mathrm{~T} 1001$ & 0.01 & 90 \\
\hline $3 \mathrm{~T} 1001$ & 0.01 & 90 \\
\hline 4T1001 & 0.01 & 90 \\
\hline 5T1003 & 0.01 & 90 \\
\hline 6T1003 & 0.01 & 90 \\
\hline 7T1003 & 0.01 & 90 \\
\hline 8T1003 & 0.01 & 90 \\
\hline
\end{tabular}

* Penamaan benda kerja didasarkan pada huruf pertama menyatakan nomer benda kerja, huruf kedua menyatakan jenis konduktor, huruf ketiga menyatakan jumlah tahap dan tiga huruf terakhir menyatakan rapat arus.

\section{Hasil Dan Pembahasan}

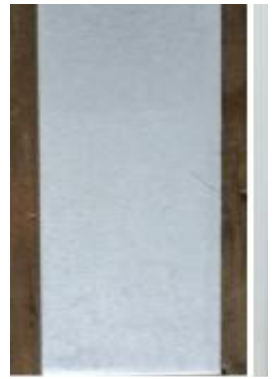

Gambar 2. Benda kerja setelah proses anodisasi 1 tahap dalam larutan $15 \%$ $\mathrm{H}_{2} \mathrm{SO}_{4}$, rapat arus $0.03 \mathrm{~A}$ selama 90 menit sebelum pewarnaan.

Tabel 1. Warna lapisan oksida aluminium setelah proses anodisasi dalam larutan $15 \% \mathrm{H}_{2} \mathrm{SO}_{4}$ sebelum pewarnaan.

\begin{tabular}{|c|c|}
\hline \multicolumn{2}{|c|}{ Identitas warna } \\
\hline RGB & HEX \\
\hline Sebelum & Sebelum \\
\hline $83,70,58$ & $\# 53463 \mathrm{a}$ \\
\hline
\end{tabular}

Pewarnaan melalui proses anodisasi menggunakan tinta printer yang tersedia secara komersial memberikan hasil yang baik $^{14}$. Sebagai hasil tersebut, dilakukan Gambar 2 menunjukan aluminium yang telah diproses anodisasi sebelum pewarnaan. Sebelum pewarnaan, benda kerja mempunyai warna putih cenderung kusam seperti warna logam aluminium pada umumnya. Identitas warna berdasarkan standar RGB dan HEX disajikan pada Tabel 1. Warna tersebut merupaka warna aluminium yang telah mengalami oksidasi dalam proses anodisasi. Selanjutnya, hasil pewarnaan menggunakan tinta printer yang tersedia secara komersial yaitu warna biru, cyan, magenta, dan hitam disajikan pada Gambar 3.

\section{A. Hasil pewarnaan}

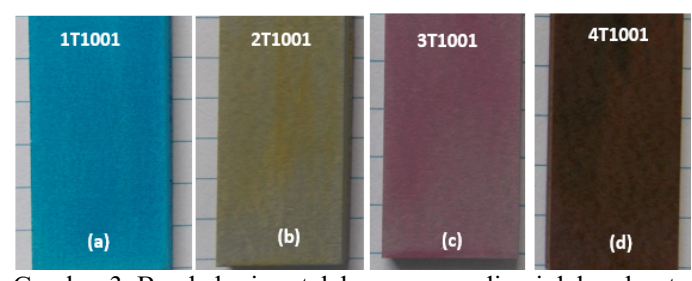

Gambar 3. Benda kerja setelah proses anodisasi dalam larutan $15 \% \mathrm{H}_{2} \mathrm{SO}_{4}$, rapat arus $0,01 \mathrm{~A} / \mathrm{cm}^{2}$, waktu 90 menit menggunakan kawat konduktor tembaga dan tinta pewarna (a) biru, (b) cyan, (c) mangenta, dan (d) hitam.

Tabel 2. Warna lapisan aluminium oksida setelah proses anodisasi 1 tahap dan pewarnaan dalam larutan $15 \% \mathrm{H}_{2} \mathrm{SO}_{4}$ dengan rapat arus $0.01 \mathrm{~A}$, dengan variasi waktu dan menggunakan kawat konduktor berupa aluminium dan tembaga.

\begin{tabular}{|c|c|c|c|}
\hline Kode Benda & RGB & HEX & Warna \\
\hline $1 \mathrm{~T} 1001$ & $86,109,105$ & $\# 566 \mathrm{~d} 69$ & Blue \\
\hline $2 \mathrm{~T} 1001$ & $103,98,76$ & $\# 67624 \mathrm{c}$ & Cyan \\
\hline $3 \mathrm{~T} 1001$ & $108,77,87$ & $\# 6 \mathrm{c} 4 \mathrm{~d} 57$ & Magenta \\
\hline $4 \mathrm{~T} 1001$ & $55,39,26$ & $\# 37271 \mathrm{a}$ & Black \\
\hline
\end{tabular}

Pewarnaan aluminium menggunakan tinta printer yang tersedia secara komersial memberikan hasil sebagaiaman 
Gambar 3. Identitas warna ditampilkan pada Tabel 2. Empat jenis warna tinta printer telah digunakan yaitu warna biru, cyan, magenta, dan hitam. Dari empat jenis warna yang digunakan, warna benda kerja yang mendekati warna tinta adalah warna biru dan magenta, sedangkan warna cyan dan warna hitam cenderung menyimpang yang ditunjukkan pada pewarnaan alumnium oksida dengan warna hitam diperoleh warna kecoklatan.. Hal ini menunjukkan bahwa terdapat interaksi yang berbeda antara masing-masing zat warna dengan aluminium oksida dari proses anodisasi. Kemungkinan, perbedaan interaksi ini disebabkan oleh jenis kation yang terdapat di dalam tinta printer, ukuran molekul, dan jenis zat warna.

\section{B. Pengaruh rapat arus terhadap kualitas warna}

Pengaruh rapat arus pewarnaan aluminium yang diproses anodisasi dalam larutan $15 \% \mathrm{H}_{2} \mathrm{SO}_{4}$, selama 90 menit disajikan pada Gambar 4-7. Gambar 4 menunjukkan pewarnaan aluminium oksida menggunakan warna biru. Hasilnya menunjukkan bahwa pada kenaikan rapat arus dari $0,01 \mathrm{ke} 0,03 \mathrm{~A} / \mathrm{cm}^{2}$ warna yang diperoleh menjadi lebih gelap dan merata. Gambar 5 menunjukkan pewarnaan aluminium oksida menggunakan warna cyan yang hasilnya menunjukkan bahwa pada kenaikan rapat arus dari $0,01 \mathrm{ke}$ $0,03 \mathrm{~A} / \mathrm{cm}^{2}$ warna yang diperoleh menjadi lebih jelas dan dapat diidentifikasi sebagai warna cyan. Pada kedua jenis warna ini, kenaikan rapat arus berpengaruh positif dalam arti kenaikan rapat arus dapat meningkatkan kualitas pewarnaan aluminium oksida.

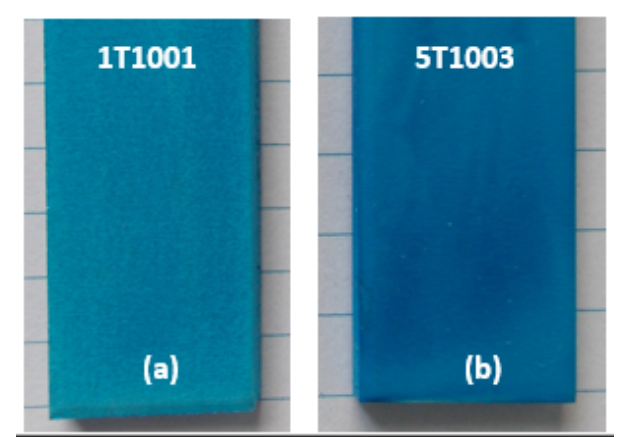

Gambar 4. $\overline{\text { Benda kerja setelah proses anodisasi dalam larutan } 15} \% \mathrm{H}_{2} \mathrm{SO}_{4}$, rapat arus (a) $0,01 \mathrm{~A} / \mathrm{cm}^{2}$, (b) $0,03 \mathrm{~A} / \mathrm{cm}^{2}$ waktu 90 menit menggunakan kawat konduktor tembaga dan pewarna tinta biru.

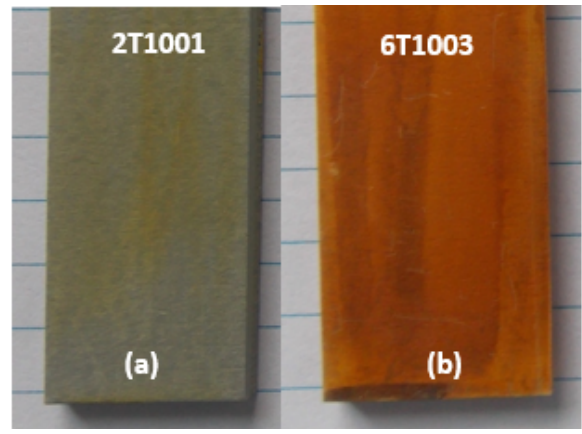

Gambar 5. Benda kerja setelah proses anodisasi dalam larutan $15 \% \mathrm{H}_{2} \mathrm{SO}_{4}$, rapat arus (a) $0,01 \mathrm{~A} / \mathrm{cm}^{2}$, (b) $0,03 \mathrm{~A} / \mathrm{cm}^{2}$ waktu 90 menit menggunakan kawat konduktor tembaga dan pewarna tinta cyan.

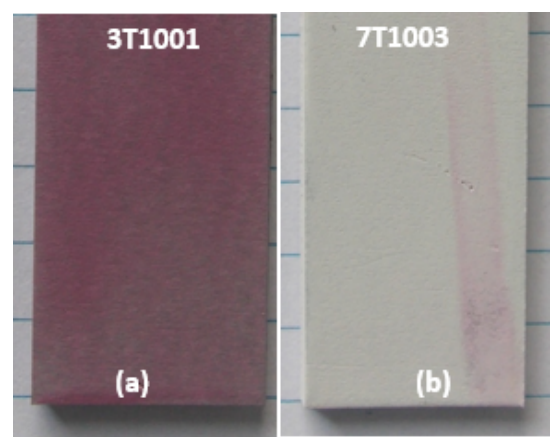

Gambar 6. Benda kerja setelah proses anodisasi dalam larutan $15 \% \mathrm{H}_{2} \mathrm{SO}_{4}$, rapat arus (a) $0,01 \mathrm{~A} / \mathrm{cm}^{2}$, (b) $0,03 \mathrm{~A} / \mathrm{cm}^{2}$ waktu 90 menit menggunakan kawat konduktor tembaga dan pewarna tinta magenta.
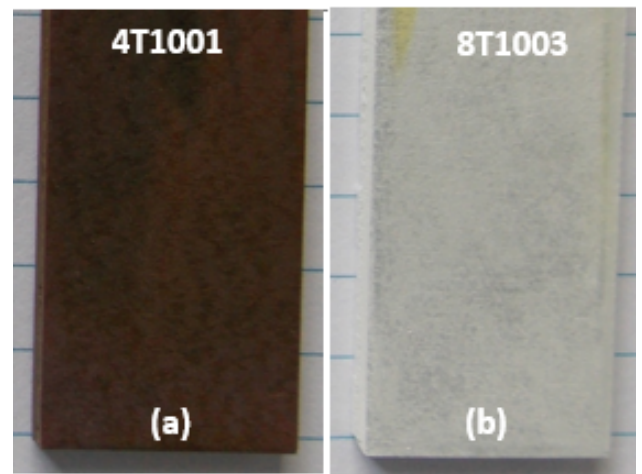

Gambar 7. Benda kerja setelah proses anodisasi dalam larutan $15 \% \mathrm{H}_{2} \mathrm{SO}_{4}$, rapat arus $0,01 \mathrm{~A} / \mathrm{cm}^{2}$, waktu 90 menit menggunakan kawat konduktor tembaga dan pewarna tinta hitam.

Gambar 6 menunjukkan pewarnaan aluminium oksida menggunakan warna magenta. Hasilnya menunjukkan bahwa pada kenaikan rapat arus dari $0,01 \mathrm{ke} 0,03 \mathrm{~A} / \mathrm{cm}^{2}$ warna yang diperoleh menjadi pudar. Demikian juga pada pewarnaan aluminium oksida menggunakan warna hitam seperti ditunjukkan pada Gambar 7. Kenaikan rapat arus dari 0,01 ke $0,03 \mathrm{~A} / \mathrm{cm}^{2}$ menjadikan warna yang diperoleh pada rapat arus rendah menjadi pudar pada rapat arus $0,03 \mathrm{~A} / \mathrm{cm}^{2}$. Pada kedua jenis warna ini, kenaikan rapat arus berpengaruh negatif dalam arti kenaikan rapat arus dapat menurunkan kualitas pewarnaan aluminium oksida.

\section{Konduktifitas hasil anodisasi}

Tabel 4 menunjukan konduktivitas aluminium oksida setelah proses anodisasi menggunakan. konduktor tembaga. Hasil pengujian konduktivitas menggunakan ohmmeter menunjukkan bahwa konduktor tembaga secara dominan menghasilkan sifat isolator. Hal ini menunjukkan bahwa proses pembentukan pori-pori lapisan oksida terjadi secara merata di seluruh permukaan aluminium.

Tabel 4. Rapat arus, voltase, dan jumlah tahap pada proses anodisasi aluminium oksida.

\begin{tabular}{|c|c|c|}
\hline Kode Benda & $\begin{array}{c}\text { Rapat Arus } \\
\left(\mathbf{A} / \mathbf{c m}^{2}\right)\end{array}$ & Konduktivitas \\
\hline $5 \mathrm{~T} 1003$ & 0,03 & Isolator \\
\hline $6 \mathrm{~T} 1003$ & 0,03 & Isolator \\
\hline $7 \mathrm{~T} 1003$ & 0,03 & Isolator \\
\hline $8 \mathrm{~T} 1003$ & 0,03 & Isolator \\
\hline
\end{tabular}




\section{KeSIMPULAN}

Proses pewarnaan melalui anodisasi untuk berbagai warna tinta printer telah dilakukan. Kualitas warna yang dihasilkan diperngaruhi dinataranya oleh rapat arus, dan jenis warna. Pada warna biru dan cyan, kenaikan rapat arus menyebabkan peningkatan kualitas warna yang diperoleh sedangkan pada warna magenta dan hitam menyebabkan penurunan kualitas warna yang diidentifikasi melalui hilangnya wrna yang telah terbentuk pada rapat arus yang lebih rendah. Benda kerja yang dihasilkan juga mempunyai sifat permukaan isolator yang berarti tahanan listrik di seluruh permukaan yang menunjukkan bahwa pembentukan pori-pori aluminium oksida terjadi secara merata pada rapat arus $0,03 \mathrm{~A} / \mathrm{cm}^{2}$ dan waktu 90 menit.

\section{UCAPAN TERIMA KASIH}

Penelitian ini didanai oleh UPT P2M Politeknik Negeri Malang DIPA No. 042.01.2.401004/2019. Penulis mengucapkan terimakasih atas bantuan yang diberikan.

\section{DAFTAR RUJUKAN}

[1] 1. Lu, J., Wei, G., Yu, Y., Guo, C. \& Jiang, L. Aluminum alloy AA2024 anodized from the mixed acid system with enhanced mechanical properties. Surfaces and Interfaces $\mathbf{1 3}$ 46-50 (2018).

[2] 2. Rambabu, P., Prasad, N. E. \& Kutumbarao, V. V. Aluminium Alloys for Aerospace Applications. (2017). doi:10.1007/978-981-10-2134-3

[3] 3. Chung, C. K., Liao, M. W., Chang, H. C. \& Lee, C. T. Effects of temperature and voltage mode on nanoporous anodic aluminum oxide films by one-step anodization. Thin Solid Films 520, 1554-1558 (2011).

[4] 4. Roshani, M., Sabour Rouhaghdam, A., Aliofkhazraei, M. \& Heydari Astaraee, A. Optimization of mechanical properties for pulsed anodizing of aluminum. Surf. Coatings Technol. 310, 17-24 (2017).

[5] 5. Jessensky, O. Self-Organized Formation of Hexagonal Pore Structures in Anodic Alumina. J. Electrochem. Soc. 145, 3735 (1998).

[6] 6. Ma, D., Li, S. \& Liang, C. Electropolishing of high-purity aluminium in perchloric acid and ethanol solutions. Corros. Sci. 51, 713-718 (2009).

[7] 7. Veys-Renaux, D., Chahboun, N. \& Rocca, E. Anodizing of multiphase aluminium alloys in sulfuric acid: in-situ electrochemical behaviour and oxide properties. Electrochim. Acta 211, 1056-1065 (2016).

[8] 8. Molchan, I. S., Molchan, T. V., Gaponenko, N. V., Skeldon, P. \& Thompson, G. E. Impurity-driven defect generation in porous anodic alumina. Electrochem. commun. 12, 693-696 (2010).

[9] 9. Stẹpniowski, W. J. \& Bojar, Z. Synthesis of anodic aluminum oxide (AAO) at relatively high temperatures. Study of the influence of anodization conditions on the alumina structural features. Surf. Coatings Technol. 206, 265-272 (2011).

[10] 10. Asoh, H., Nishio, K., Nakao, M., Tamamura, T. \& Masuda, H. Conditions for Fabrication of Ideally Ordered Anodic Porous Alumina Using Pretextured Al. J. Electrochem. Soc. 148, B152 (2001).

[11] 11. Nakajima, D., Kikuchi, T., Natsui, S. \& Suzuki, R. O. Mirror-finished superhydrophobic aluminum surfaces modified by anodic alumina nanofibers and self-assembled monolayers. Applied Surface Science 440, (Elsevier B.V., 2018).
[12] 12. Han, X. Y. \& Shen, W. Z. Improved two-step anodization technique for ordered porous anodic aluminum membranes. $J$. Electroanal. Chem. 655, 56-64 (2011).

[13] 13. Donahue, C. J. \& Exline, J. A. Anodizing and Coloring Aluminum Alloys. 711-715 (2014).

[14] 14. Buwono, H. P. et al. Tinta Printer Sebagai Pewarna Aluminium Oksida Yang Stabil Pada Proses Anodisasi Coloring. J. Elem. 5, 62 (2019). 